Eur. J. Clin. Chem. Clin. Biochem.

Vol. 32, 1994, pp. 539-542

(C) 1994 Walter de Gruyter \& Co.

Berlin - New York

\title{
Comparison of the Determination of Magnesium by Methylthymol Blue Spectrophotometry and Atomic Absorption Spectrophotometry
}

\author{
By Petra M. M. Saur ', S. Zielmann ', Andrea Roth ${ }^{2}$, L. Frank', G. Warneke ${ }^{2}$, F.-B. M. Ensink ${ }^{1}$ and A. Radke \\ 1 Zentrum für Anaesthesiologie, Rettungs- und Intensivmedizin \\ 2 Zentrum Innere Medizin \\ Georg August Universität Göttingen, Göttingen, Germany
}

(Received January 25/April 6, 1994)

Summary: Plasma samples $(n=155)$ of 30 patients on an intensive ward were analysed for magnesium simultaneously by atomic absorption spectrophotometry (AAS) and methylthymol blue spectrophotometry. Methylthymol blue spectrophotometry was performed at the bedside, using two different multianalysers, Easy ST 1 and Easy ST 2, Merck, D-Darmstadt.

Precision was $12.2 \%$ (Easy ST 1 ) and $17.1 \%$ (Easy ST 2), and the average value was $0.89 \mathrm{mmol} / \mathrm{l}$, which was above the expected range $(0.72-0.88 \mathrm{mmol} / \mathrm{l})$.

Accuracy was $16.25 \%$ (Easy ST 1) and $8.75 \%$ (Easy ST 2). Analyser 2 was more accurate (8.75\% versus $6.25 \%$ ) but less precise (17.1\% versus $12.2 \%)$ than analyser 1 .

Precision of AAS was between the expected values of 0.69 and $0.84 \mathrm{mmol} / \mathrm{l}$. Easy ST and AAS gave significantly different values $(p<0.0001)$ for 155 measurements.

Comparison of AAS and methylthymol blue spectrophotometry showed that methylthymol blue spectrophotometry produced higher values than AAS (mean difference $0.186 \mathrm{mmol} / \mathrm{l}$ ).

Furthermore, analyses of 40 samples of a standardized plasma concentration with methylthymol blue spectrophotometry showed a very low precision (15.3\%).

Easy ST cannot be assigned for urinary measurements of magnesium. Experimentally measured samples gave unaccountable results.

\section{Introduction}

The development of atomic absorption spectrophotometry (AAS) in 1955 by Walsh has made it possible to analyse magnesium in biological media (1). This method is now the "golden standard" for the analysis of this important cation in human blood and urine (2).

Other methods such as methylthymol blue spectrophotometry, which can be adapted to a multianalyser for bedside measurements, have also been developed $(3-5)$.
In this study, a new bedside multianalyser (Easy ST) with methylthymol blue spectrophotometry was tested for the measurement of magnesium in plasma and urine.

\section{Methods}

With the approval of the local ethics committee, a magnesium tolerance test was performed in 30 patients. To monitor magnesium status, magnesium was analysed in plasma and urine simultaneously by the standardized AAS method and by methylthymol blue spectrophotometry adapted to a bedside analyser, Easy ST. 
Plasma samples $(n=155)$ of the 30 patients of an intensive ward were taken from indwelling femoral or radial arteries, centrifuged for 2 minutes at $10000 \mathrm{~min}^{-1}$ (Eppendorf centrifuge 5415, DHamburg) and stored at $-20^{\circ} \mathrm{C}$.

Samples analysed by AAS (Elektrolytautomat FL 6, Zeiss, D-Oberkochen) were diluted with strontium chloride. Two different Easy ST (Easy ST, Merck, D-Darmstadt) analysers were used for the methylthymol blue spectrophotometry method.

Plasma samples $(n=130)$ of 22 patients were analysed by Easy ST 1 and 25 plasma samples of 8 patients were measured by Easy ST 2.

In the AAS method, magnesium is measured by photometry of an acetylene-air-flame, using a calcium-magnesium cathode lamp. Calibration, equalization and calculation of magnesium concentrations were done automatically.

In the methylthymol blue spectrophotometry method, magnesium forms a complex with methylthymol blue in alkaline medium. Absorbance of this complex is proportional to the magnesium content of the sample and is measured photometrically at $578 \mathrm{~nm}$. Calcium is eliminated by forming a complex with barium-ethylenebis-(oxyethylenenitrilo)-tetraacetate, which does not absorb in this wavelength.

Precision was determined by analysing a standardized plasma containing $0.8 \mathrm{mmol} / \mathrm{l}$ (Precinorm, Boehringer Mannheim, Mannheim). Precision was expressed as variation coefficients and accuracy by the percentage deviation of the average from the real value (6).

The expected values of measurement by methylthymol blue spectrophotometry and the difference between AAS and methylthymol blue spectrophotometry values were tested with t-tests.

Accuracy was defined as the percentage difference between the determined and the expected value (7); this was less than $10 \%$.

\section{Results}

Precision of AAS was determined between 0.69 and $0.84 \mathrm{mmol} / \mathrm{l}$.

Measurements of the standardized plasma concentration of $0.8 \mathrm{mmol} / 1$ (Precinorm, Boehringer Mannheim, Mannheim) is shown in table 1.

Fourty samples were analysed in two different Easy ST analysers. Precision was $12.2 \%$ (Easy ST 1) and 17.1\%

Tab. 1 Measurements of standardized magnesium plasma concentrations by Easy ST 1 and Easy ST 2

\begin{tabular}{lccc}
\hline & $\begin{array}{l}\text { Easy } \\
\text { ST 1 }+2 \\
\mathrm{n}=40\end{array}$ & $\begin{array}{l}\text { Easy } \\
\text { ST 1 } \\
\mathrm{n}=17\end{array}$ & $\begin{array}{l}\text { Easy } \\
\text { ST 2 } \\
\mathrm{n}=23\end{array}$ \\
\hline Mean value [mmol/l] & 0.89 & 0.93 & 0.87 \\
Standard deviation [mmol/1] & 0.14 & 0.11 & 0.15 \\
Median [mmol/1] & 0.90 & 0.90 & 0.87 \\
Minimum [mmol/1] & 0.63 & 0.72 & 0.63 \\
Maximum [mmol/1] & 1.11 & 1.10 & 1.11 \\
25\%-Quantil [mmol/1] & 0.80 & 0.90 & 0.78 \\
75\%-Quantil [mmol/1] & 1.01 & 1.00 & 1.02 \\
Precision [\%] & 15.30 & 12.20 & 17.10 \\
Accuracy [\%] & 11.25 & 16.25 & 8.75 \\
P-value & 0.49 & 0.09 & 0.71 \\
Significance & none & none & none \\
\hline
\end{tabular}

(Easy ST 2), and the average value of measurements was $0.89 \mathrm{mmol} / \mathrm{l}$, which was not in the expected range of 0.72 and $0.88 \mathrm{mmol} / \mathrm{l}$.

Accuracy was $16.25 \%$ (Easy ST 1) and $8.75 \%$ (Easy ST 2); the average accuracy of $11.25 \%$ is not significantly different from the authorized value of $10 \%$. Moreover, this method was out of control, because 7 subsequent measurements lay on one side of the mean value. Although analyser 2 was more accurate, it was less precise $(17.1 \%$ versus $12.2 \%)$ than analyser 1 .

Figures 1 and 2 show the comparison of magnesium concentrations in plasma measured by AAS, Easy ST 1 (fig. 1) and Easy ST 2 (fig. 2).

For most of the samples, the Easy ST gave a higher value than the AAS (mean difference $0.186 \mathrm{mmol} / \mathrm{l}$ ).

For 155 measurements, Easy ST and AAS gave significantly different values $(p<0.0001)$.

The average difference between AAS and methylthymol blue spectrophotometry measurements was 0.186 $\mathrm{mmol} / \mathrm{l}$ (Easy ST 1: 0.192 for 130 measurements and Easy ST 2: $0.196 \mathrm{mmol} / \mathrm{l}$ for 25 mẹașurements).

Standard deviation was $0.196 \mathrm{mmol} / \mathrm{l}$ (Easy ST 1: 0.206 $\mathrm{mmol} / \mathrm{l}$ and Easy ST 2: $0.134 \mathrm{mmol} / \mathrm{l})$.

The methylthymol blue spectrophotometry method on the Easy ST was not assigned for urinary measurements of magnesium, because the results were too inaccurate and too imprecise.

\section{Discussion}

Diagnosis and therapy of disorders of electrolytes in human body fluids are clinically very important. In contrast to sodium, potassium and calcium, it is not yet usual to analyse magnesium at the bedside on the intensive ward, although these patients are at high risk of developing magnesium deficiency $(8-10)$.

It is therefore important to measure magnesium in plasma, urine and other biological fluids easily, quickly and accurately, and with as little expense as possible.

AAS is nowdays accepted as the "golden standard method". Paschen showed the method to have very high precision (1\%) in the measurement of different magnesium concentrations (2). Nisbet \& Owen (11) analysed a shift of calibration of only $0.22 \mathrm{mmol} / 1$ in AAS.

Compared with AAS, the methylthymol blue spectrophotometry method on the multianalyser Easy ST was less precise and less accurate in measuring magnesium plasma concentrations, and it was therefore not assigned for urinary measurements. This is an important disad- 


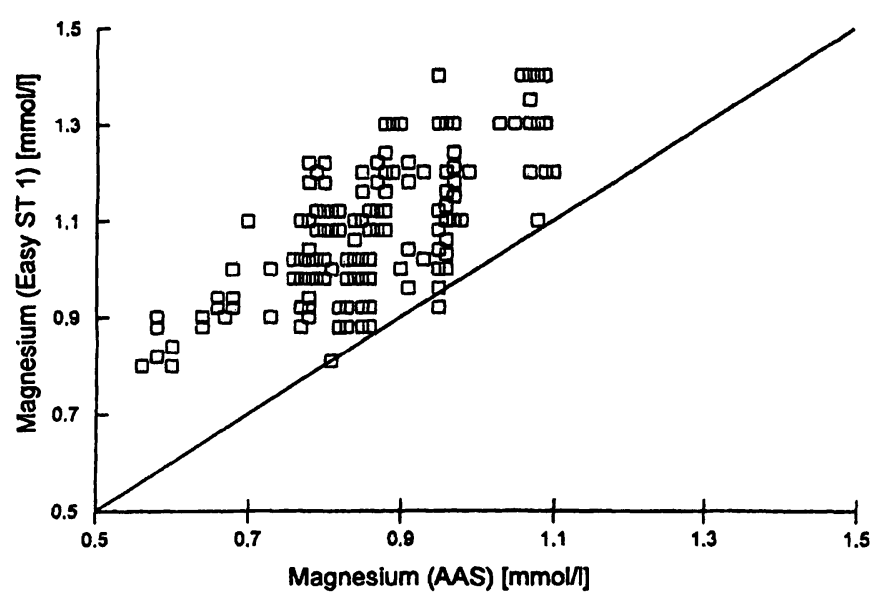

Fig. 1 Magnesium-plasma-concentrations measured by AAS and Easy ST 1.

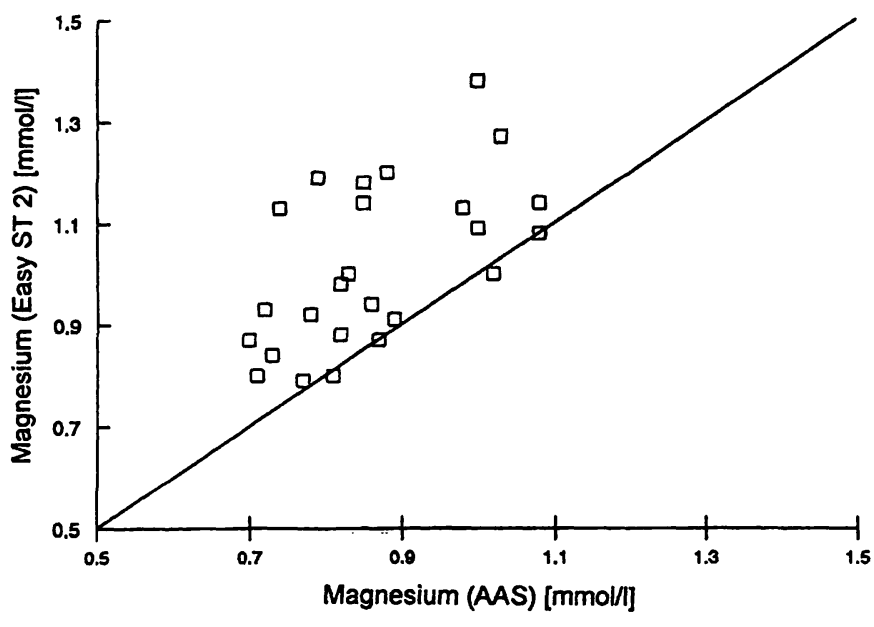

Fig. 2 Magnesium-plasma-concentrations measured by AAS and Easy St 2.

vantage, because magnesium tolerance testing has been shown to be the most reliable method for diagnosing magnesium depletion $(9,12-15)$.

Easy ST recorded higher concentrations than AAS, thereby falsifying the diagnosis of hypomagnesaemia.

With a standard deviation of $0.196 \mathrm{mmol} / \mathrm{l}$, values were in the normal range of magnesium plasma concentra- tions of 0.70 to $1.10 \mathrm{mmol} / \mathrm{l}$, showing the low precision of the analysing method.

Because of the low accuracy of the measurements by Easy ST, a further validation of the magnesium values investigated by AAS and methylthymol blue spectrophotometry was omitted.

Wills (16) and Wong (4) found a high correlation (Wills: $r=0.99$ and Wong: $r=0.95$ ) between magnesium concentrations in plasma measured with methylthymol blue spectrophotometry and AAS.

Both authors used a du Pont Automatic Clinical Analyser for methylthymol blue method.

Wong (1983) analysed 114 serum samples of 39 healthy employees and 75 in-patients, which ranged in values from 0.3 to $1.9 \mathrm{mmol} / \mathrm{l}$. Results from the two methods generally agreed or differed by only $0.05 \mathrm{mmol} / \mathrm{l}$, with the exception of a few values above $1 \mathrm{mmol} / \mathrm{l}$, when the methylthymol blue spectrophotometry method produced results 0.1 to $0.15 \mathrm{mmol} / \mathrm{l}$ higher than the AAS method.

Wills (1986) analysed magnesium concentrations in 78 hospital patients and found an overall correlation coefficient of 0.97 . Six samples were visibly contaminated with bilirubin and showed lower methylthymol blue spectrophotometry magnesium values than those obtained by AAS.

However, these authors did not give information about accuracy and precision of the analysers they used, so that one might consider that the high correlation found did not exclude systemic faults.

Our findings suggest that the method of methylthymol blue spectrophotometry magnesium analysis by Easy ST, especially for the values of hypomagnesaemia, is not precise enough for use as a bedside method for magnesium measurements.

It is necessary to analyse urinary magnesium elimination, in order to determine magnesium substitution requirements, and for estimating magnesium deficiency by magnesium tolerance testing. The bedside multianalyser Easy ST is not suitable for this purpose.

\section{References}

1. Walsh, A. (1955) The application of atomic absorption spectra to chemical analysis. Spectrochem. Acta 7, 108-117.

2. Paschen, K. (1982) Magnesium-Bestimmung im Serum, Plasma, Urin und anderren Körperflüssigkeiten mittels Atomabsorptions-Spektralphotometrie (AAS). In: Magnesium und Tokolyse. Bayreuther Gespräch 26. September 1981. Fortschritte der Medizin (Weidinger, H., ed.) pp. 32-40, Gauting.

3. Connerty, H. V., Lau, H. S. C. \& Brigs, A. R. (1971) Spectrophotometric determination of magnesium by use of methylthymol blue. Clin. Chem. 17, 661-662.

4. Wong, E. T., Rude, R. K., Singer, F. R. \& Shaw, S. T. (1983) A high prevalence of hypomagnesiemia and hypermagnesiemia in hospitalized patients. Am. J. Clin. Pathol. 79, 348352.

5. Wacker, W. E. C. (1987) Measurement of magnesium in human tissues and fluids: $\mathrm{A}$ historical perspective. Magnesium 6, 61-64.

6. Eggers, R. H. \& Bircher, J. (1988) Inadequate reporting of analytical quality control in the clinical pharmalogical literature. Eur. J. Clin. Pharmacol. 34, 319-321. 
7. Jauck, F. \& Spitzauer, S. (1988) Klinische Chemie, Urban \& Schwarzenberg, München.

8. Chernow, B., Smith, J., Rainey, T. G. \& Finton, C. (1982) Hypomagnesemia: Implications for the critical care specialist. Crit. Care Med. 10, 193-196.

9. Ryzen, E., Elbaum, N., Singer, F. R. \& Rude, R. K. (1985) Parenteral tolerance testing in the evaluation of magnesium deficiency. Magnesium 4, 137-147.

10. Reinhart, R. A. \& Desbiens, N. A. (1985) Hypomagnesemia in patients entering the ICU. Crit. Care Med. 13, 506-507.

11. Nisbet, J. A. \& Owen, J. A. (1979) Calibration drift in the automated determination of calcium and magnesium by atomic absorption. Clin. Chim. Acta 92, 367-371.

12. Gullestad, L., Soyland, E., Kjekshus, J. \& Aase, O. (1986) Magnesium deficiency in a clinical population. Magnesium Bull. 8, 251.

13. Holm, C. N., Jepsen, J. M., Sjogarard, G. \& Hessow, I. (1987) Magnesium load test in the diagnosis of magnesium deficiency. Hum. Nutr. Clin. Nutr. 4IC, 301-306.
14. Caddell, J. L. \& Reed, G. F. (1989) Validity of the parenteral magnesium load test for mature mammals. Magnesium 8, 65-70.

15. Danielson, B. G., Johannnșon, G. \& Ljunghall, S. (1979) Magnesium metabolism in healthy subjects. Scand. J. Urol. Nephrol. (Suppl.) 51, 49-73.

16. Wills, M. R., Sunderman, F. W.; \& Savory, J. (1986) Methods for estimation of serum magnesium in clinical laboratories. Magnesium 5, 317-327.

\section{P. M. M. Saur}

Zentrum für Anaesthesiologie, Rettungs- und Intensivmedizin Georg August Universität Göttingen Robert-Koch-Straße 40 D-37070 Göttingen Germany 